\title{
ANAESTHESIA TECHNICIANS IN QUEBEC: THE BACKGROUND AND THE ROLE
}

\author{
Luc Perreault
}

\begin{abstract}
Anaesthesia technicians are respiratory technologists who received their education in CEGEPs. Every respiratory technologist, when he finishes his course, is specially trained to become an anaesthesia technician.

The tasks are delegated to anaesthesia technicians according to the task description of the anaesthetist. This specialist in the current practice must comply with the principles of the art of medicine: he makes a diagnosis by evaluating the risk of each patient who will be anaesthetised and by evaluating the patient's state along the course of anaesthesia and operation; then he decides on the treatment, i.e. he chooses the anaesthetic technique that is suitable for him and he modifies it during the operation according to the needs of the patient. In the diagnosis-treatment procedure, we find a part of decision and a part of execution. It is clear that the decision is reserved exclusively to the anaesthetist but the execution of certain tasks may be delegated to technicians.

The task description for the anaesthesia technician has been developed in accordance with these principles and in accord with the new "Guide to Anaesthesia Practice" of the Corporation of Physicians of the Province of Quebec that does not agree with double booking of anaesthetists.

Finally, we discuss employment of the technicians in the various operating rooms according to the variety of surgery that is done in each room and the work load that is generated.

Experience with this organization has convinced us that the anaesthesia technicians, through their clinical and technical contribution, provide an infrastructure in a department of anaesthesia which permits smooth and efficient functioning of the department. It also relieves the anaesthetist of certain energy-consuming and time-consuming tasks.
\end{abstract}

Key Words: ANAESTHESia, Technicians.

DURING THE PAST FEW YEARS, the Association of Anaesthetists of Quebec has helped to establish among the various departments of anaesthesia a new category of people called anaesthesia technicians. The uninitiated may wonder who these technicians are, where they come from and what they do.

The structure of allied health professions improved between the years 1960 and 1970 in the province of Quebec. The creation of the CEGEP (College for General and Professional Teaching) favoured standardization of training in health technologies. There are six or seven technologies, according to their main interest, and their common point is the three year College level training of their students. We call them Nursing Technology, Laboratory Technology, Respiratory Technology, Radiology Technology, etc. Each of these technologies has a specific course of basic sciences followed by study of the

Luc Perreault, M.D., Director, Department of Anaesthesia, Maisonneuve-Rosemont Hospital, 5415, l'Assomption blyd, Montreal, P.Q, Canada H1T 2M4. techniques of each technology and clinical training in hospitals.

Anaesthesia technicians are respiratory technologists. Because the respiratory technology course includes teaching of respiratory and cardiovascular physiology plus the techniques of respiratory resuscitation, the Association of Anaesthetists of Quebec has chosen them to become anaesthesia technicians. The basic course has been modified to include anaesthesia technique and, actually, all the candidates who get their College Level Diploma in Respiratory Technology are qualified anaesthesia technicians.

Anaesthesia Technicians are basically respiratory technologists who work in anaesthesia departments on a full time or part time basis.

The role of the anaesthesia technician differs from that of the American Nurse Anaesthetist. Nurse Anaesthetists give anaesthetics without the physical presence of an anaesthetist; anaesthesia technicians do not give anaesthetics and work under direct supervision and in the physical presence of the anaesthetist. 
TABLE I

AnAlysis of Tasks in ANaEsthesia

\begin{tabular}{|c|c|}
\hline Decision & Execution \\
\hline \multicolumn{2}{|l|}{ Diagnosis } \\
\hline 1 Evaluation of physical status & $\begin{array}{l}\text { + Case History: family and personal past-history } \\
\text { + Chart review: biological \& physiological evaluation }\end{array}$ \\
\hline $\begin{array}{l}2 \text { Evaluation of anaesthetic evolution management } \\
\text { Diagnosis of complications }\end{array}$ & $\begin{array}{l}\text { Installation of monitoring devices } \\
\text { Observation of vital signs } \\
\text { Special tests }\end{array}$ \\
\hline $\begin{array}{l}3 \text { Post-anaesthetic evaluation } \\
\text { Diagnosis of complications }\end{array}$ & $\begin{array}{l}\text { Installation of monitoring devices } \\
\text { Observation of vital signs } \\
\text { Special tests }\end{array}$ \\
\hline \multicolumn{2}{|l|}{ Treatment } \\
\hline $\begin{array}{l}1 \text { Choice of anaesthetic technique } \\
\text { Premedication }\end{array}$ & $\begin{array}{l}\text { + Explanation of anaesthetic technique to the patient } \\
\text { Drug administration (premedication) }\end{array}$ \\
\hline $\begin{array}{l}2 \text { Installation of anaesthetic technique } \\
\text { Modification of anaesthetic technique }\end{array}$ & $\begin{array}{l}\text { Execution of anaesthetic technique } \\
+ \text { Induction } \\
\text { Setting of flowmeters } \\
\text { Opening of vaporisers } \\
\text { Setting of articial ventilation } \\
\text { Preparation and administration of drugs } \\
\text { Recovery of techniques } \\
\text { Assistance in techniques of regional anaesthesia } \\
+ \text { Execution of regional anaesthesia techniques }\end{array}$ \\
\hline $\begin{array}{l}3 \text { Usual post-anaesthesia care } \\
\text { Treatment of complications }\end{array}$ & $\begin{array}{l}\text { Installation of monitoring devices } \\
\text { Monitoring of vital signs } \\
\text { Preparations and administration of drugs } \\
\text { Execution of special techniques }\end{array}$ \\
\hline
\end{tabular}

Legend: 1. Pre-anaesthetic

2. Per-anaesthetic

3. Post-anaesthetic

+ Must be performed by an anaesthetist

We have considered that, as stated by Adriaensen and Van de Walle, ${ }^{1}$ the system that permits an anaesthetist to give more than one anaesthetic at the same time with the help of allied health personnel is a system that has efficiency as its first goal rather than safety.

Throughout this paper, we will review the tasks of anaesthetists and it will be possible to point out the place and the role of anaesthesia technicians. The tasks of technicians have been established after an evaluation of the anaesthetist's task, as described by Gravenstein et al. ${ }^{2}$

\section{TASK Description of ANAESTHETISTS}

In current practice, the anaesthetist must comply with principles of the art of medicine: he makes a diagnosis by evaluating the risk for each patient who will be anaesthetised, according to the presence or the absence of other pathology. Subsequently he decides on the treatment; that is, he makes a choice of the technique of anaesthesia based on the risk to the patient and the kind of operation. During the course of anaesthesia, he must constantly reconsider this diagnosistreatment procedure, since observation of the patient's clinical state guides him in the conduct of anaesthesia.

Table $I$ is an illustration of this concept which shows how the diagnosis and treatment are applied to the different stages of anaesthesia. This process contains elements of decision and of execution. It is clear that all decisions are the responsibility of the anaesthetist. In the field of execution, a number of tasks must be reserved to the anaesthetist and some others may be delegated to people specially trained to do them. This is when the anaesthesia technician or the recovery room nurse can be helpful. Among these tasks we find the observation of clinical signs of the patient, be it the vital signs or the signs that express the reactions of the patient towards the operation he is subjected to. All 
those signs are observed through monitoring devices attached to the patient.

In the recovery room, the anaesthetist leaves his patient in the hands of a competent nurse, who has intensive care unit training or the equivalent, and the nurse continues observation of clinical signs until the patient is fully awake.

\section{Task Description of ANaEsthesia TECHNICIAN}

The clinical and technical tasks of the technician can be defined on the basis of the preceding discussion.

\section{Clinical Tasks}

We must include in clinical tasks all that is directly related to the patient and delegated by the anaesthetist. All these tasks are in the field of the execution;

1. Installation of monitoring devices on the patients: stethoscope, sphygmomanometer, cardiac monitor.

2. Assistance to the anaesthetist during induction of and recovery from anaesthesia and during maintenance when necessary.

3. Opening of flowmeters and vaporisers.

4. Setting of the ventilator according to the anaesthetist's prescription.

5. Monitoring and registration of vital signs: pulse rate, blood pressure, temperature, blood loss, urine flow rate.

6. Preparation and administration of drugs under immediate supervision of the anaesthetist.

7. Assistance to the anaesthetist in regional anaesthesia or pain clinics.

\section{Technical Tasks}

Technical tasks assigned to anaesthesia technicians have the same importance as clinical tasks. They include preparation and checking of all equipment and materials used in anaesthesia:

1. Checking of anaesthesia apparatus.

2. Checking of cardiac monitors.

3. Sterilization and preparation of strain gauges.

4. Checking of laryngoscopes.

5. Checking, cleaning and refurnishing of anaesthesia cart containing tracheal tubes, intravenous solutions, syringes, needles, drugs and all materials used in anaesthesia.

6. Checking and preparation of all material and drugs used in regional anaesthesia.

7. Planning and supervision of cleaning and sterilization of anaesthesia equipment.
8. Checking of order book of all material used in anaesthesia.

A few technical tasks may be transferred to an orderly with an adequate training, but they must be supervised by a technician.

\section{USE of ANAESTHESIA TECHNICIANS}

After this brief description of the tasks of the anaesthetist and the anaesthesia technician, it is important to describe how we employ anaesthesia technicians in the anaesthesia department.

First, it is important to say that the new "Guide to Anaesthesia Practice" published by the Corporation of Physicians of the Province of Quebec ${ }^{3}$ and prepared in close cooperation with the Association of Anaesthetists of Quebec does not condone simultaneous administration of two anaesthetics by one anaesthetist. This means the elimination of the practise of using anaesthesia technicians to monitor the patient's clinical signs during the absence of the anaesthetist. This does not exclude the possibility of giving some clinical tasks to the technician, since it happens that the anaesthetist may be overloaded and that he needs some help for appropriate care of the patient.

With this rule in mind let us review the tasks, considering the three main phases of anaesthesia: induction, maintenance and recovery.

Induction: The anaesthesia technician assists the anaesthetist in all the techniques employed during induction: he helps to fix the intravenous catheter, performs mask ventilation before tracheal intubation, helps the anaesthetist for intubation, connects anaesthesia circle and respirator if needed, sets flow rates and volume of ventilation according to the anaesthetist's prescription. He also assists the physician with invasive techniques like TVC catheter introduction, arterial canula, Swan-Ganz catheters, etc. Finally, the anaesthesia technician assists the anaesthetist during techniques for induction of regional anaesthesia.

Maintenance: In simple cases of surgery without sophisticated techniques, when the patient does not need time consuming techniques such as fast administration of multiple transfusions, the use of hypotensive drugs, etc., the anaesthetist usually works alone.

In complicated cases where many things must be done at the same time, the anaesthesia technician may be helpful: this may happen during neurosurgery with or without hypotension, in cardio-vascular surgery, pulmonary surgery, a few cases of orthopedic surgery, extensive ab- 
PYRAMIDAL STRUCTURE

FOR THE PRACTICE OF ANAESTHESIA

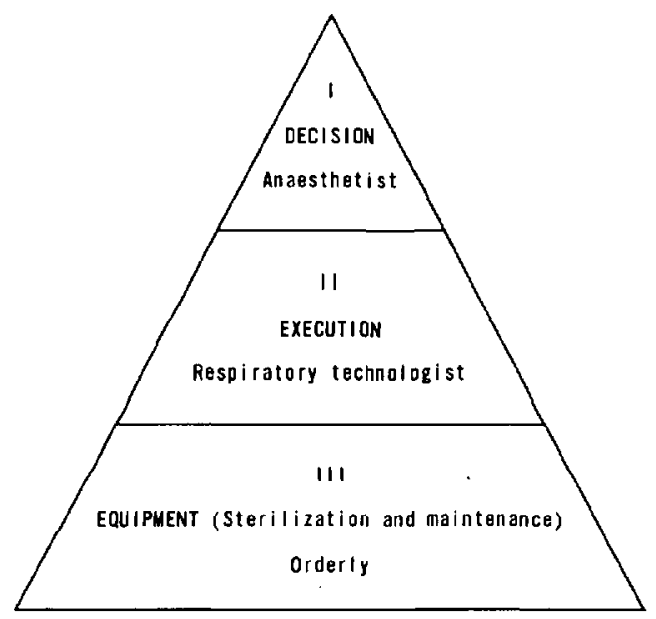

I Responsible for 1,11 and 111
II Performs delegations on level 11

FIgURE 1 Representation of the organization of functions in a department of anaesthesia

dominal operations, when it is necessary to maintain good anaesthetic stability along with good monitoring of clinical signs and administration of blood, intravenous fluids and drugs.

In cases of very long operations when the monitoring of stable vital signs may become lax, the presence of a technician for a period of time provides double checking and increases the security of the patient.

Recovery: As previously described, the technician assists the anaesthetist all through the recovery period.

\section{ANAESTHETIST/TECHNICIAN RELATION}

In view of this assistance by technicians, the relation between the number of anaesthetists and technicians in the operating room varies according to the kind of surgery or anaesthesia being done.

In cases where technicians assist induction, one technician for two anaesthetists is a reasonable ratio. The technician may assist both anaesthetists alternately. In theatres where there are many small operations, such as tonsillectomies, it is useful to have the permanent help of a technician. This is also true in extensive surgery and during very long operations.
From what has been said, it becomes clear that the presence of anaesthesia technicians permits development of a pyramidal structure to define responsibility for the tasks done in an anaesthesia department. (Figure 1).

The anaesthetist is responsible for all decisions concerning the conduct of anaesthesia. He is also responsible for the execution of the various tasks. However, he may allow the technician to do a few clinical and technical tasks under supervision.

The technician is responsible for execution of the clinical tasks that he is allowed to do and for the technical tasks. He may, however, have certain technical tasks done by an orderly (cleaning, sterilization) but he is responsible for the quality of the work.

\section{Conclusion}

The development of anaesthesia technology and its evolution according to the principles described herein allows the departments of anaesthesia to use people with standard education and training. They work in a well informed way because they are well taught in the course in Respiratory Technology. They are the infrastructure of anaesthesia departments especially for the technical duties which make departments run smoothly and efficiently.

Anaesthetists should consider using these technicians when they want some tasks to be done by allied health people. However, in the recovery rooms, it is necessary to have qualified nurses because of the specific care that is necessary therein.

There are between 180 and 200 anaesthesia technicians working in anaesthesia departments in the Province of Quebec. They are all very satisfied with their role and the "Corporation des Inhalothérapeutes du Québec' "seems happy with this orientation for its members. It is not possible at this time to appreciate the contribution of this system to patient safety, but we know that it has brought a great help in the anaesthetist's life.

The next step in our program should be an evaluation that would permit us to know if this setting decreases morbidity or mortality, especially those "unpredictable accidents" happening during small operations on healthy subjects.

\section{REFERENCES}

1. Adriaensen, H. \& van de Walle, J. The influence of staff and personnel on the safety of the patient during anesthesia. Acta Anesthesiol. Bels. 29(1): $37-43$ (1978). 
2. Gravenstein, J.S. \& Steinhaus, J.E. Analysis of Manpower in Anesthesiology. Anaesthesiology, 33(3): p. 35-357 (1970).
3. Guide to the practice of Anaesthesia. Corp. of Physicians of Quebec (to be published) (1980).

\section{RÉSUMÉ}

Les techniciens en anesthésie sont des inhalothérapeutes gradués des CEGEPs. Tout inhalothérapeute, à la fin de son cours, possède l'entrainement nécessaire pour travailler comme technicien en anesthésie.

Les tâches attribuées au technicien en anesthésie découlent de l'étude des tâches de l'anesthésiste. Ce dernier, dans la pratique de son art procède à l'élaboration d'un diagnostic en faisant l'évaluation pré-opératoire de son malade, et en évaluant le comportement de ce dernier en regard de l'aggression anesthésique et chirurgicale; ensuite il établit un traitement, i.e. il choisit la technique anesthésique appropriée et il la modifie en cours de route selon les besoins du malade. Ce processus diagnostic/traitement comporte en lui-même un aspect décisionnel et un aspect d'exécution. Il est entendu que la décision est le privilège exclusif de l'anesthésiste. C'est au niveau de l'exécution que la délégation de tâches peut se faire.

La description des tâches du technicien en anesthésie tient compte de ces principes et respecte aussi le nouveau "Guide d'exercice de l'Anesthésie" de la Corporation Professionnelle des Médecins du Québec qui recommande que l'anesthésiste ne soit assigné qu'à un seul malade à la fois.

Enfin, on discute de la manière d'assigner le technicien dans les différentes salles d'anesthésie en tenant compte de la variété de chirurgie qui se fait dans chacune des salles et de la charge de travail qui en découle.

L'expérience acquise avec ce système montre que les techniciens en anesthésie, tant par leurs tâches cliniques que par leurs tâches techniques, constituent l'infrastructure qui permet à un département d'anesthésie de fonctionner harmonieusement et efficacement en déchargeant l'anesthésiste de tâches serviles nécessitant beaucoup de temps et d'énergie. 